\title{
LEGALIDADE DO RAS COMO ESTUDO AMBIENTAL NO LICENCIAMENTO DE HABITAÇÕES DE INTERESSE SOCIAL
}

\author{
Joel Medeiros Bezerra* \\ Marianna Domingos da Silva** \\ Jessica Rafaelly Almeida Lopes ${ }^{* * *}$
}

RESUMO: Considerando a importância das políticas públicas ambientais, no que concernem ao processo administrativo de licenciamento ambiental, o estudo trata-se de uma análise da legalidade do Relatório Ambiental Simplificado (RAS) como estudo ambiental nos processos de licenciamento de habitações de interesse social, fazendo um questionamento sobre a obrigatoriedade de tal estudo nos processos de licenciamento. Concomitantemente, a pesquisa apresenta uma análise do Termo de Referência (TR) elaborado pelo IDEMA, COPAM e COEMA, bem como a realização de um confronto entre os TR's do RN, PB e CE, respectivamente, levando em consideração a qualidade das informações dispostas no documento, buscando propor sugestões de melhoria, caso necessário. Em virtude das informações mencionadas e dos aspectos relacionados à legalidade do RAS como estudo ambiental para as atividades destinadas à construção de habitações de interesse social, o Termo de Referência disponibilizado pelo IDEMA atende ao seu objetivo, porém necessita de complementações no item que trata do Meio Biótico, de forma que minimize a possibilidade de problemas decorrentes da elaboração do RAS. No entanto, devido às dificuldades de acesso aos TR's da COPAM e COEMA, o que impossibilitou a avaliação dos itens no TR.

PALAVRAS-CHAVE: Processos de Licenciamento; RAS; Termo de Referência.

\section{LEGALITY OF RAS AS ENVIRONMENTAL STUDY IN THE WARRANTS OF SOCIALLY-BUILT HOUSES}

ABSTRACT: The importance of environmental public policies with regard to the

Doutor em Engenharia Agrícola, docente Adjunto da Universidade Universidade Federal Rural do Semi-Árido (UFERSA), Centro Multidisciplinar de Pau dos Ferros, curso de Engenharia Ambiental \& Sanitária. Brasil. E-mail: joel.medeiros@ufersa.edu.br

** Especialista em Gestão Ambiental pelo Instituto Federal do Rio Grande do Norte (IFRN). Analista ambiental do IDEMA

*** Discente de Engenharia Ambiental e Sanitária pela Universidade Federal Rural do Semi-Árido (UFERSA), Brasil. 
administrative process of environmental warranting is well-known. Current study analyzes the legality of the Simplified Environmental Report (RAS) as an environmental study in warrants for socially-built houses. Analysis questions the mandatory aspect of such studies in the warrant processes. Research also analyzes the Term of Reference (TR) prepared by IDEMA, COPAM and COEMA, and contrasts the TRs of $\mathrm{RN}, \mathrm{PB}$ and $\mathrm{CE}$, respectively, taking into consideration the information quality in the document and forwarding suggestions for any improvement. Due to the fact the that information mentioned above and the aspects related to the legality of RAS as an environmental study aim at the building of socially-built houses, the TR by IDEMA attends its goal. However, the item on Biotic Medium should be complemented to lessen the possibility of problems in the elaboration of RAS. However, due to difficulties in accessing TR of COPAM and COEMA, an evaluation of items of the respective TRs was unavailable.

KEY WORDS: Warrants; RAS; Term of reference.

\section{INTRODUÇÃO}

É obrigatório o procedimento administrativo como o licenciamento ambiental de toda e qualquer atividade efetiva e/ou potencialmente poluidora. Por meio da obtenção da licença ambiental, o empreendedor está legalmente respaldado a realizar sua atividade de acordo com os padrões e legislações ambientais vigentes.

Os órgãos que têm competência para licenciar e fiscalizar as atividades e empreendimentos com alto potencial poluidor degradador nos Estados do Rio Grande do Norte (RN), Paraíba (PB) e Ceará (CE) são o Instituto de Desenvolvimento Sustentável e Meio Ambiente do Rio Grande do Norte (IDEMA), o Conselho de Proteção Ambiental (COPAM), e o Conselho Estadual de Meio Ambiente (COEMA), respectivamente. Além disso, é competência dos órgãos a elaboração dos Termos de Referência (TR) de cada estudo ambiental exigido nas diversas atividades passíveis de licenciamento ambiental.

Os estudos ambientais são fundamentais no processo de licenciamento ambiental, pois permitem analisar e relacionar os possíveis impactos ambientais e suas medidas mitigadoras, além dos impactos sociais, uma vez que os empreendimentos ou as atividades que envolvem diretamente a população do entorno, sobretudo, sabendo que o licenciamento ambiental tem dentre suas finalidades a função social. 
Com efeito, ao analisar as atividades de construção civil, a crescente especulação imobiliária no Estado diz respeito à atividade de construção de conjuntos habitacionais e condomínios residenciais, em que foi possível encontrar uma diferença nos check lists das habitações de interesse social.

Tal orientação aplica-se somente a empreendimentos com impacto ambiental de pequeno porte, mediante definição do órgão ambiental competente, fundamentada em parecer técnico.

O RAS compõe os estudos relativos aos aspectos ambientais concernentes à localização, instalação, operação e ampliação de uma atividade ou empreendimento, apresentados como subsídios para a concessão da Licença Prévia, contendo as informações relativas ao diagnóstico ambiental da região de inserção do empreendimento, sua caracterização, a identificação dos impactos ambientais e das medidas de controle pertinentes.

De fato, é possível observar que mesmo respaldada por resoluções do Conselho Nacional do Meio Ambiente (CONAMA), a construção de condomínios e conjuntos habitacionais segue duas vertentes que se divergem de acordo com o tipo de financiamento, se é recurso próprio ou subsídios do Governo Federal. Sendo que esse último se enquadra através dos programas de interesse social vigentes no país, pois o estudo ambiental exigido neste caso é menos exigente e burocrático tanto na elaboração, quanto na análise, sobretudo o próprio processo de licenciamento conta com uma tramitação bem mais simplificada.

Contudo, diante dessa problemática, o presente artigo tem como objetivo analisar a legalidade e o Termo de Referência do RAS como estudo ambiental nos processos de licenciamento ambiental das habitações de interesse social, bem como a realização de um confronto entre os TR's do RN, $\mathrm{PB}$ e CE.

\section{MATERIAL E MÉTODOS}

Para a realização deste trabalho foi feita uma pesquisa sobre o tema habitações de interesse social, com ênfase no licenciamento ambiental e nos fundamentos jurídicos relacionados. 
Por meio de uma pesquisa exploratória e descritiva, que segundo Gil (2008) são métodos que visam desenvolver, esclarecer e modificar conceitos e ideias, tendo em vista a formulação de problemas mais precisos. Ainda de acordo com o autor, a pesquisa descritiva tem por finalidade descrever as características de determinado fato, estabelecendo uma relação entre as variáveis estudas. Além disso, proporcionou uma visão geral acerca do assunto em questão.

O desenvolvimento deste estudo se deu por meio de dados fornecidos pelo IDEMA, COEMA e COPAM para subsidiar a elaboração do RAS com vistas a ressaltar os procedimentos de licenciamento adotados.

Em seguida foi obtido um Termo de Referência do RAS para efetuar uma análise qualitativa das informações constantes nos documentos, buscando possíveis falhas para, caso necessário, sugerir melhorias.

Por outro lado, em virtude da dificuldade de acesso ao documento do COEMA e COPAM, o que impossibilitou a avaliação dos itens no TR, bem como a realização de um confronto entre os TR's do RN, PB e CE, para que assim fosse possível uma análise quanto ao potencial poluidor degradador das habitações de interesse social.

\subsection{LICENCIAMENTO AMBIENTAL DE EMPREENDIMENTOS DE INTERESSE SOCIAL}

A SEMACE, por meio da Resolução do COEMA n ${ }^{\circ} 10$, de 11 de junho de 2015, lista as atividades passíveis de licenciamento ambiental no Estado do Ceará, com classificação e enquadramento pelo Potencial Poluidor/Degradador, conforme o Quadro 1 para habitações de interesse social tem-se os seguintes parâmetros: 
Quadro 1. Atividades passíveis de licenciamento ambiental

\begin{tabular}{|c|c|c|c|}
\hline 09.00 & \multicolumn{2}{|c|}{ Contrução Civil } \\
\hline 09.01 & $\begin{array}{c}\text { Empreendimentos Multifamiliares - Sem Infraestrutura } \\
\text { (Condomínios e Conjuntos Habitacionais) }\end{array}$ & $\mathrm{M}$ & \\
\hline 09.02 & $\begin{array}{c}\text { Empreendimentos Multifamiliares - Com Infraestrutura } \\
\text { (Condomínios e Conjuntos Habitacionais) }\end{array}$ & $\mathrm{B}$ & \multirow{2}{*}{$\begin{array}{c}\text { Construção Civil Terminais e } \\
\text { Depósitos }\end{array}$} \\
\hline 09.03 & $\begin{array}{c}\text { Empreendimentos Unifamiliares - Sem Infraestrutura } \\
\text { (Condomínios e Conjuntos Habitacionais) }\end{array}$ & $\mathrm{M}$ & \\
\hline 09.04 & $\begin{array}{c}\text { Empreendimentos Unifamiliares - Com Infraestrutura } \\
\text { (Condomínios e Conjuntos Habitacionais) }\end{array}$ & $\mathrm{B}$ & \\
\hline
\end{tabular}

E ainda, de acordo com referida resolução, conforme o porte e potencial poluidor/degradador do empreendimento, obra ou atividade, têm-se os critérios de análise de licenciamento ou autorização ambiental como mostra o Quadro 2.

GRUPO 09.00 - CONSTRUÇÃO CIVIL 
Quadro 2. Critérios de análise do licenciamento ou autorização ambiental por atividade produtiva

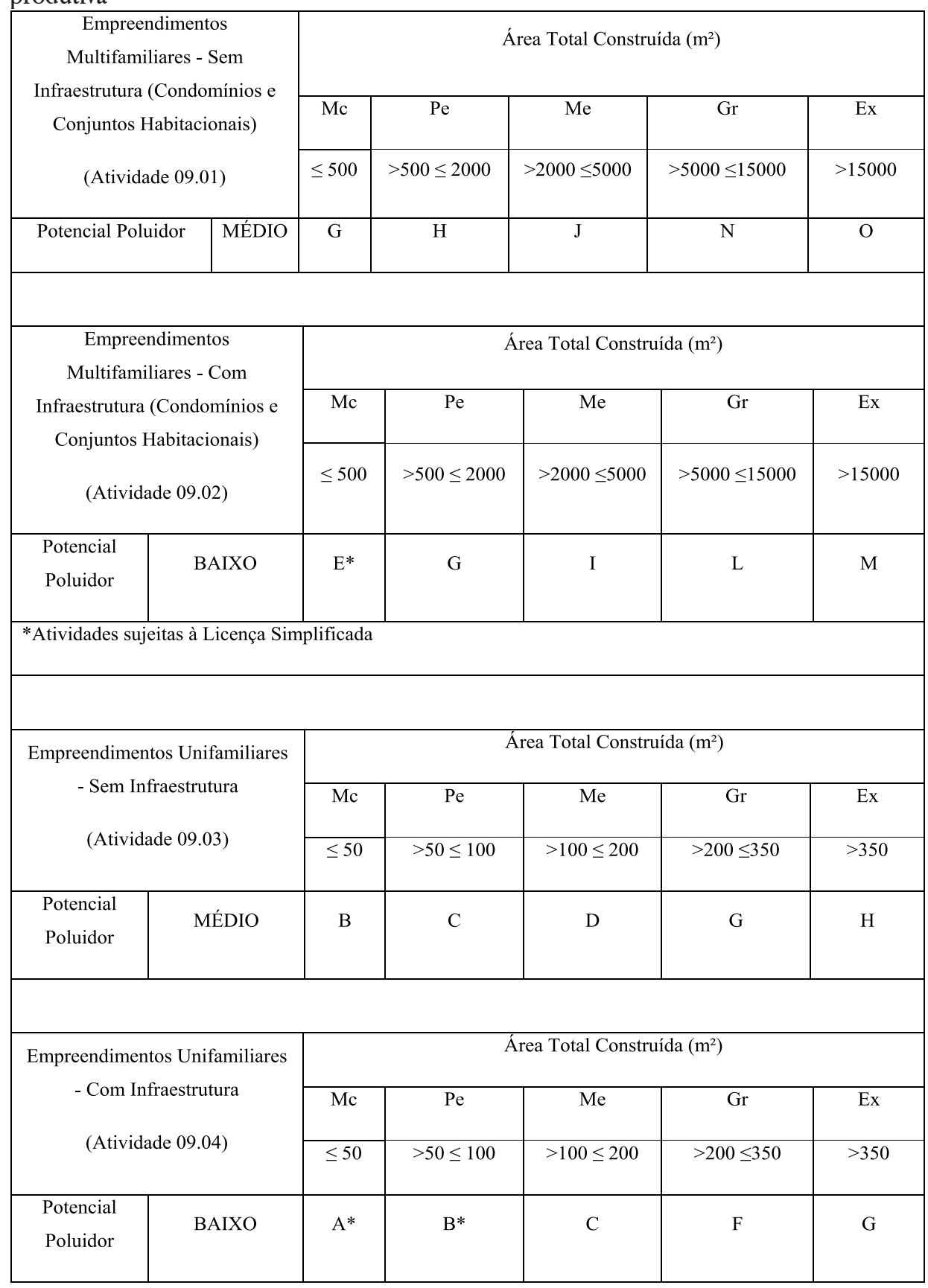


Já a SUDEMA, através do COPAM, regulamentado pelo Decreto Estadual $\mathrm{n}^{\mathrm{O}}$ 21.120 , de 20 junho de 2000, dispõe sobre os critérios para expedição do licenciamento ambiental no Estado da Paraíba, e ainda de acordo com Norma Administrativa 108 da SUDEMA, classifica as tipologias e potencial poluidor dos empreendimentos, como mostrado no Quadro 3, utilizando-se os parâmetros de área construída, investimento total e número de funcionários chega-se ao porte de empreendimento, assim como os enquadramentos considerando a combinação das características, natureza, potencial poluidor e porte.

Quadro 3. Potencial poluidor de empreendimentos ou atividades objeto de licenciamento

\begin{tabular}{|l|c|c|c|c|c|c|c|c|c|c|c|c|}
\hline $\begin{array}{l}\text { 6. Imobiliários (Parcelamento de } \\
\text { Solo) }\end{array}$ & P/M/G & & & & & & & & & & & \\
\hline
\end{tabular}

Entretanto, o Quadro 4 identifica o porte dos empreendimentos ou atividades, os quais são enquadrados conforme os seguintes indicadores: área total construída; valor do investimento; número de funcionários e/ou área total do projeto.

6. Empreendimentos Imobiliários (Parcelamento de Solo) 
Quadro 4. Parâmetro potencial poluidor para cada empreendimento ou atividade

\begin{tabular}{|c|c|c|c|c|c|c|}
\hline & & & \multicolumn{4}{|c|}{ Número de Unidades Habitacionais } \\
\hline $\begin{array}{c}\text { Conjuntos } \\
\text { Habitacionais }\end{array}$ & $=10$ & $>10 \mathrm{e}=30$ & $=50$ & $>50 \mathrm{e}=100$ & $>100 \mathrm{e}=200$ & $>200$ \\
\hline (Grupo 6.1) & G & $\mathrm{H}$ & I & $\mathbf{J}$ & $\mathrm{L}$ & $\mathrm{M}$ \\
\hline
\end{tabular}

OBS: Para os empreendimentos financiados com recursos de programas sociais do Governo - 0,3 UFRPB por unidade habitacional. - LP

$=0,5$ UFRPB por unidade habitacional - L.I

$=0,3$ UFRPB por unidade habitacional - L.O

Obs: Considerando que estes valores não cobrirão os custos despendidos pela SUDEMA, o município deverá arcar, quando necessário, com as despesas decorrentes de hospedagens, veículos e combustíveis.

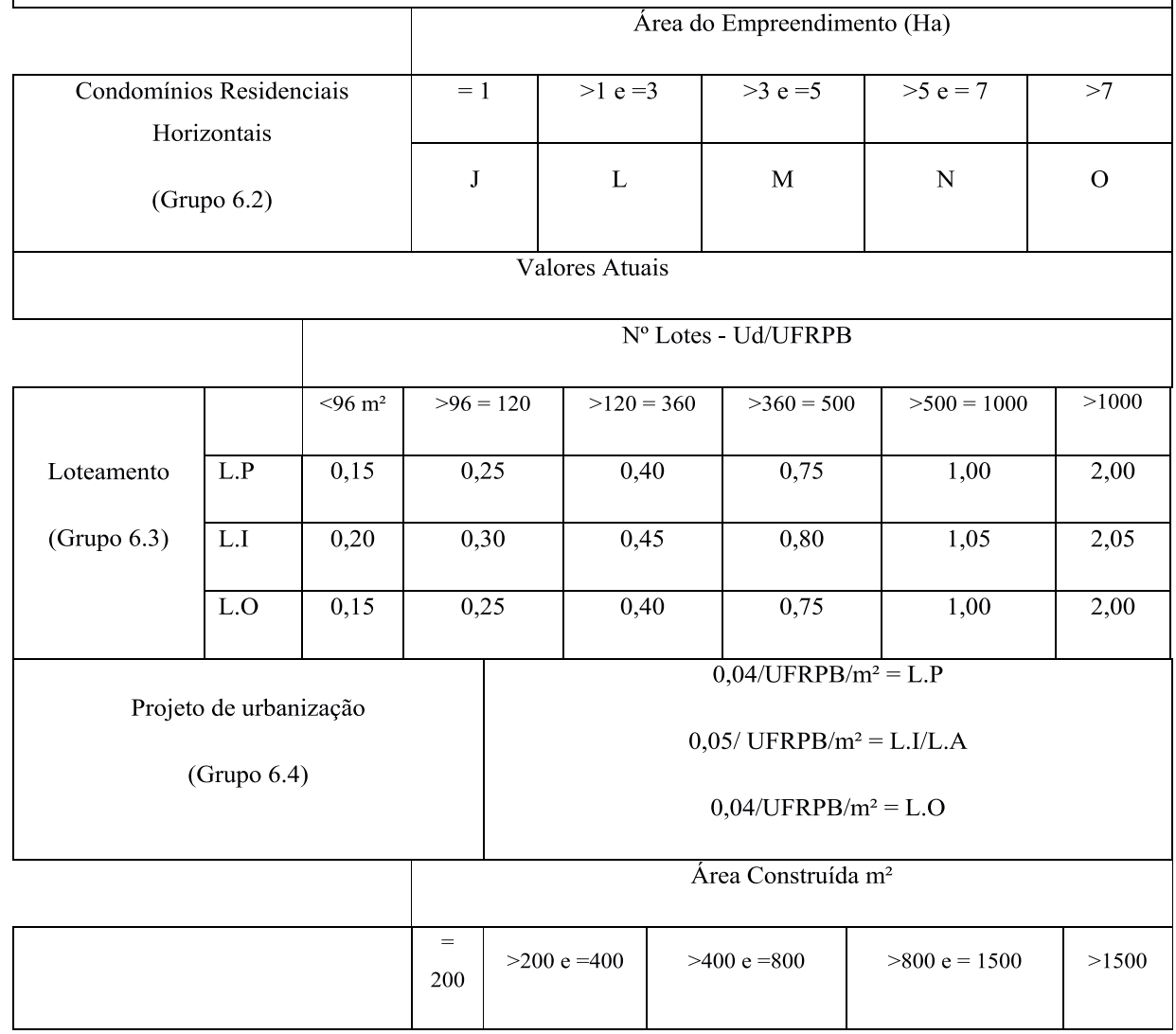


No enquadramento das atividades passíveis de licenciamento ambiental, como destacado no Quadro 5, o IDEMA utiliza a Lei Complementar do Rio Grande do Norte $\mathrm{n}^{\mathrm{O}} 272$, de 03 de março de 2004, mais precisamente a Resolução CONEMA 004/2006. As construções de conjuntos habitacionais e condomínios residenciais devem atender aos seguintes parâmetros:

\section{Construção Civil}

Quadro 5. Parâmetros de enquadramento do licenciamento ambiental para condomínios e conjuntos habitacionais.

\begin{tabular}{|c|c|c|c|c|c|c|c|c|c|c|}
\hline \multirow{2}{*}{$\begin{array}{c}\text { Atividades/ } \\
\text { Empreendimentos }\end{array}$} & \multicolumn{6}{|c|}{ Porte } & \multicolumn{4}{|c|}{$\begin{array}{l}\text { Potencial Poluidor/Degra- } \\
\text { dador }\end{array}$} \\
\hline & $\begin{array}{c}\text { Parâmetro } \\
\text { Adotado para } \\
\text { Classificação }\end{array}$ & Mic & $P$ & M & G & Exc & $\mathrm{Ar}$ & Água & $\begin{array}{l}\text { Solo/ } \\
\text { Subsolo }\end{array}$ & Geral \\
\hline Condomínios & $\begin{array}{c}\text { Unidade } \\
\text { Habitacional } \\
\text { (UH) }\end{array}$ & $\begin{array}{l}>10 \mathrm{a} \\
\leq 50\end{array}$ & $\begin{array}{l}>50 \mathrm{a} \\
\leq 150\end{array}$ & $\begin{array}{l}>150 \\
a \leq 300\end{array}$ & $\begin{array}{l}>300 \\
a \leq 600\end{array}$ & $>600$ & $\mathrm{P}$ & $P$ & G & M \\
\hline $\begin{array}{l}\text { Conjuntos Habita- } \\
\text { cionais }\end{array}$ & $\begin{array}{c}\text { Unidade } \\
\text { Habitacional } \\
\text { (UH) }\end{array}$ & $\begin{array}{l}>25 \mathrm{a} \\
\leq 50\end{array}$ & $\begin{array}{l}>50 \mathrm{a} \\
\leq 200\end{array}$ & $\begin{array}{l}>200 \\
a \leq 800\end{array}$ & $\begin{array}{c}>800 \\
\quad a \\
\leq 3.200\end{array}$ & $>3.200$ & $\mathrm{P}$ & $\mathrm{P}$ & G & M \\
\hline
\end{tabular}

\subsection{ANÁLISE DOS ITENS DO RELATÓRIO AMBIENTAL SIMPLIFICADO}

O documento do Termo de Referência do IDEMA para a elaboração do RAS referente ao licenciamento ambiental simplificado de empreendimentos de interesse social é composto por três páginas de orientações, onde existe um roteiro básico com diretrizes e normativas a serem restritamente seguidas. Nele são apresentados onze tópicos principais, são eles considerados:

1. Identificação do empreendedor e do empreendimento;

2. Identificação da empresa responsável pela elaboração do RAS;

3. Descrição do projeto;

4. Área de influência; 
5. Diagnóstico ambiental;

6. Identificação e análise dos impactos ambientais;

7. Medidas mitigadoras;

8. Programa de acompanhamento e monitoramento;

9. Conclusões;

10. Equipe técnica;

11. Bibliografia.

Desta forma, fica clara a relevância da elaboração e desenvolvimento dos RAS que contemplem os quesitos apresentados no TR do IDEMA. No entanto, diante da dificuldade ao acesso dos documentos do COPAM, COEMA não foi possível realizar este confronto.

\section{RESULTADOS E DISCUSSÃO}

\subsection{O TERMO DE REFERÊNCIA}

Após a análise do TR do RAS do IDEMA, e da legislação pertinente ao tema deste estudo, verificou-se que existem problemáticas referentes às ferramentas utilizadas no diagnóstico ambiental, especificamente no contexto do item do meio biótico. Sendo assim, tem-se como proposta a retificação do mesmo, em que deve-se manter o texto original que trata da descrição da vegetação nativa e antrópica, e a respectiva fauna.

Contudo, em relação à flora, uma das sugestões é que seja realizada a caracterização florística e fitossociológica da vegetação existente na área do empreendimento.

A composição florística deve ser um dos primeiros aspectos a ser analisado em áreas florestais que são objetos de pesquisa, manejo da silvicultura, e qualquer outra atividade que envolva a utilização dos recursos vegetais. É essencial entender a composição florística para se desenvolver estudos adicionais sobre a estrutura da dinâmica da floresta (CARVALHO, 1997). 
A fitossociologia é o ramo da ecologia vegetal mais amplamente utilizado para diagnóstico quali-quantitativo das formações vegetacionais. Vários pesquisadores defendem a aplicação de seus resultados no planejamento das ações de gestão ambiental, como no manejo florestal e na recuperação de áreas degradadas (ISERNHAGEN, 2001).

Diante dos apontamentos, sugere-se que seja também apresentada uma lista de espécies encontradas no empreendimento, informando no mínimo: o nome vulgar, o nome científico, as famílias, distinção entre exóticas ou nativas e indicar se está em risco de extinção.

Estas informações são primordiais para o conhecimento da realidade do local onde será instalado o empreendimento. Elas seguem um padrão de diagnóstico ambiental estabelecido no artigo $6^{\circ}$ da Resolução CONAMA n ${ }^{\circ}$ 001/86.

A indicação das áreas de preservação permanente é necessária, pois estas são protegidas pelo Código Florestal (Lei ${ }^{0}$ 12.651/12) e outras leis vigentes no país, tal como a CONAMA 303/2002. A destruição ou dano destas áreas é crime estabelecido na Lei 9.605/98, atualizada pela Lei 12.305/2010.

No tocante à fauna, deve-se listar as espécies de invertebrados e vertebrados, informando no mínimo: o nome vulgar, o nome científico, as famílias, apresentar como a espécie foi registrada. Estas informações são fundamentais para o entendimento da dinâmica faunística da localidade.

Também se faz necessário informar as espécies indicadoras da qualidade ambiental, de valor científico e econômico, raras e ameaçadas de extinção, respeitando o padrão de diagnóstico ambiental estabelecido no artigo $6^{\circ}$ da Resolução CONAMA $n^{\circ}$ 001/86.

Por fim, devem-se apresentar estudos sobre a densidade populacional (estimativa do número de indivíduos por unidade de área), diversidade (riqueza, dominância, entre outros) e relações ecológicas existentes (competição, predação, mutualismo, etc.).

Estes estudos ajudam na compreensão do funcionamento das comunidades, subsidiando a tomada de decisões quanto ao processo de avaliação da viabilidade e compatibilidade do empreendimento ao local a ser inserido. Segundo Pinto-Coelho (2002), o estudo da biodiversidade refere-se às relações quantitativas entre riqueza e abundância dentro das comunidades. 
Vale salientar que as ações antropogênicas que têm maior impacto no meio ambiente é a construção, por isso a importância de estudos que minimizem os efeitos negativos de suas atividades, visando o compromisso ambiental, bem como estimular a consciência ambiental, por meio da implementação de empreendimentos habitacionais de interesse social de forma sustentável (SCHEIDT et al., 2010).

Se fizermos uma comparação dos check list das duas modalidades de construção de condomínios e conjuntos habitacionais, veremos que além da declaração do agente financiador para a comprovação dos subsídios, as habitações de interesse social exigem a apresentação do RAS.

A construção de habitações de interesse social conta com importantes instrumentos legais, dentre eles a Lei $\mathrm{n}^{\circ}$ 10.998/04, que manteve o Programa de Subsídio à Habitação de Interesse Social (PSH). Essa lei tem como objetivo:

Art $2^{\circ} \mathrm{O}$ PSH objetiva tornar acessível a moradia para os segmentos populacionais de renda familiar alcançados pelas operações de financiamento ou parcelamento habitacional de interesse social, realizadas por instituições financeiras autorizadas a funcionar pelo Banco Central do Brasil ou pelos agentes financeiros do Sistema Financeiro da Habitação - SFH, na forma definida pelo Conselho Monetário Nacional.

A Lei Complementar 272 de 2004 do Estado do Rio Grande do Norte estabelece em seu artigo $\mathrm{n}^{\mathrm{O}} 56$ a exigibilidade de estudos ambientais em empreendimentos suscetíveis de causar impacto ao meio ambiente. Especificamente no inciso II, o RAS é mencionado:

Art. 56. O licenciamento de empreendimentos suscetíveis de causar impacto no meio ambiente deverá, quando necessário, ser instruído com a realização de Estudos Ambientais. Parágrafo único. Consideram-se Estudos Ambientais todos aqueles apresentados como subsídio para a análise do licenciamento ambiental requerido, tais como:

I - Relatório de Controle Ambiental (RCA);

II - Relatório Ambiental Simplificado (RAS);

III - Plano de Controle Ambiental (PCA);

IV - Programa de Monitoramento Ambiental (PMA);

V - Estudo de Viabilidade Ambiental (EVA);

VI - Relatório de Avaliação e Desempenho Ambiental (RADA);

VII - Relatório de Risco Ambiental (RRA);

VIII - Relatório de Avaliação Ambiental (RAA); e

IX - Análise de Risco (AR). 
Por sua vez, o CONAMA, em 2009, a partir da resolução 412, estabeleceu critérios e diretrizes para o licenciamento ambiental de novos empreendimentos destinados à construção de habitações de interesse social. Nesta resolução, para viabilizar o processo de licenciamento, é exigido um Relatório Ambiental Simplificado, o RAS, levando em consideração a função de prevenção de danos e riscos ao ser humano e ao meio ambiente.

Embora sendo enquadrados em processos de licenciamento simplificado, ou seja, quando um único processo compreende a localização, instalação e operação do empreendimento, a exigibilidade do RAS é exigida por lei de acordo com o artigo $6^{\circ}$ da Resolução CONAMA 412 em que está previsto:

Art. $6^{\circ}$ No licenciamento ambiental simplificado para novos empreendimentos habitacionais de interesse social deverão ser apresentados ao órgão ambiental licenciador, no mínimo, os seguintes documentos:

I - Requerimento de licença ambiental;

II - Manifestação favorável do órgão responsável pela emissão de autorizações para a supressão de vegetação;

III - Outorga de recursos hídricos, quando couber;

IV - Declaração municipal de conformidade do empreendimento com a legislação municipal aplicável ao uso e ocupação do solo;

V - Relatório técnico contendo a localização, descrição, o projeto básico e o cronograma físico de implantação das obras com a respectiva anotação de responsabilidade técnica;

VI - Relatório Ambiental Simplificado - RAS; e

VII - Relatório de Detalhamento dos Programas Ambientais, quando couber, a critério do órgão ambiental licenciador.

No que concerne à delimitação deste trabalho aos RAS, isso ocorreu, pois é o principal estudo ambiental para obtenção de licença para empreendimento de interesse social, mais especificamente pelo seu papel no diagnóstico ambiental, avaliação de impactos e proposição de planos de monitoramento e medidas mitigadoras.

De acordo com Sánchez (2008) os resultados dos estudos de base formam uma descrição e análise da situação atual de uma área de estudo feita por meio de levantamentos de componentes e processos do meio ambiente físico, biótico e antrópico e de suas interações, o que é usualmente chamado de diagnóstico ambien- 
tal, um retrato da situação pré-projeto, ao qual virá se contrapor um prognóstico ambiental, ou seja, uma projeção da provável situação futura do ambiente potencialmente afetado, caso a proposta em análise seja implementada; também se pode fazer um prognóstico ambiental considerando que a proposta em análise não seja implementada.

A análise do Termo de Referência foi realizada com a intenção de localizar possíveis falhas ou omissões em seu conteúdo e, dentro do analisado, apenas no tópico 5.1, referente ao meio biótico, foi considerado parcialmente insatisfatório.

O texto do meio biótico, presente no termo de referência, apresenta a seguinte definição: Caracterizar e mapear a vegetação nativa e a zona antrópica, indicando a necessidade ou não de supressão vegetal para a implantação das instalações; caracterizar a fauna local (IDEMA, 2012).

Levando em consideração a importância do RAS, no que se refere à identificação dos impactos ambientais relacionados ao empreendimento em questão, faz-se necessário que ele contenha, no mínimo, os elementos básicos que integram o Estudo de Impacto Ambiental. Vejamos o que diz a artigo $6^{\circ}$, inciso I, alínea a, da Resolução CONAMA n ${ }^{0}$ 001/86 sobre o conteúdo mínimo do Estudo de Impacto Ambiental (EIA):

Art. $6^{\circ}$ - O estudo de impacto ambiental desenvolverá, no mínimo, as seguintes atividades técnicas:

I - Diagnóstico ambiental da área de influência do projeto completa descrição e análise dos recursos ambientais e suas interações, tal como existem, de modo a caracterizar a situação ambiental da área, antes da implantação do projeto, considerando: [...]

b) o meio biológico e os ecossistemas naturais - a fauna e a flora, destacando as espécies indicadoras da qualidade ambiental, de valor científico e econômico, raras e ameaçadas de extinção e as áreas de preservação permanente; [...] (BRASIL, 1986, p. 02, grifo nosso).

Diante do exposto pelo artigo supracitado, o item sobre o Meio Biótico merece uma ampliação nas informações referentes à fauna e à flora, de maneira que produza maior consistência ao assunto que é fundamental.

Não se pretende indicar a inserção de todo o conteúdo exigível para um EIA dentro de um RAS, a finalidade é dar mais informações para evitar problemas futuros como: a devolução do RAS para complementação das informações, o que 
acarreta em demora na conclusão do processo de licenciamento; ou a omissão de informações que em caso de acidentes naquele empreendimento, tragam penalidades jurídicas tanto para o empreendedor, como para o órgão licenciador.

\subsection{LEGALIDADE DO RAS COMO ESTUDO AMBIENTAL NO LICENCIAMENTO DE HABITAÇÕES DE INTERESSE SOCIAL}

De acordo com as informações fornecidas no decorrer deste estudo podemos relembrar alguns trechos e adicionar novos fragmentos da legislação, que auxiliarão na compreensão da legalidade do RAS.

A Constituição Federal no seu artigo $225, \S 1^{\circ}$, inciso IV estabelece que se deve exigir, na forma da lei, para instalação de obra ou atividade potencialmente causadora de significativa degradação do meio ambiente, estudo prévio de impacto ambiental, a que se dará publicidade (BRASIL, 1988).

\section{CONCLUSÃO}

Em virtude das informaçóes mencionadas e dos aspectos relacionados à legalidade do RAS como estudo ambiental para as atividades destinadas à construção de habitações de interesse social, o Termo de Referência disponibilizado pelo IDEMA atende ao seu objetivo, porém necessita de complementações no item que trata do Meio Biótico, de forma que minimize a possibilidade de problemas decorrentes da elaboração do RAS.

Quanto ao RAS, as informações apresentadas no decorrer deste estudo evidenciaram a sua legalidade como instrumento de avaliação de impactos para o licenciamento da construção de condomínios destinados às habitações de interesse social. A utilização do RAS para o licenciamento da atividade encontra respaldo, principalmente, na Resolução no 412/09 do Conselho Nacional de Meio Ambiente. Porém, o CONAMA como responsável pelas resoluções deveria dar uma maior atenção aos empreendimentos não contemplados pelo programa de subsídios, pois os impactos ambientais dessas construções podem, por muitas vezes, ser maiores e 
mais significativos, implicando em uma deficiência na análise do processo de licenciamento, bem como na sua tramitação devido o estudo ambiental ser solicitado, geralmente, após a vistoria na área do empreendimento.

\section{REFERÊNCIAS}

BRASIL. Constituição da República Federativa do Brasil, de 5 de outubro de 1988. 11. ed. São Paulo: Atlas, 1998.

BRASIL. Lei $\mathrm{n}^{0} 10.998,15$ de dezembro de 2004. Altera o programa de subsídio à habitação de interesse social. Diário Oficial da República Federativa do Brasil. Brasília, 2004.

BRASIL. Lei $\mathrm{n}^{\mathrm{O}}$ 12.305, de 02 de agosto de 2010. Institui a Política Nacional de Resíduos Sólidos. Dispõe sobre seus princípios, objetivos e instrumentos, bem como sobre as diretrizes relativas à gestão integrada e ao gerenciamento de resíduos sólidos. Diário Oficial da República Federativa do Brasil. Brasília, 2010.

BRASIL. Lei $\mathrm{n}^{\mathrm{0}}$ 12.651, de 25 de maio de 2012. Institui o novo Código Florestal Brasileiro. Dispõe sobre a proteção da vegetação nativa. Diário Oficial da República Federativa do Brasil. Brasília, 2012.

CARVALHO, J. O. P. de. Dinâmica de florestas tropicais e sua implicação para o manejo florestal sustentável. In: CURSO de manejo florestal sustentável: tópicos em manejo florestal sustentável. Curitiba-PR. EMBRAPA/CNPF, 1997. 253p. (Documentos, 34).

COEMA - Conselho Estadual do Meio Ambiente. Resolução no 10 , de 11 de junho de 2015. Dispõe sobre a atualização dos procedimentos, critérios, parâmetros e custos aplicados aos processos de licenciamento e autorização ambiental no âmbito da Superintendência Estadual do Meio Ambiente - SEMACE. Ceará, CE. Disponível em: < http://www.semace.ce.gov.br/wp-content/uploads/2014/01/RESOLU\%C3\%87\%C3\%83O-COEMA-N\%C2\%BA-10-DE-11-DE-JUNHO-DE-2015.pdf>. Acesso em: 20 mar. 2017. 
CONAMA - Conselho Nacional de Meio Ambiente. Resolução no 001, de 23 de janeiro de 1986. Brasília: DOU de 07/02/1986.

CONAMA - Conselho Nacional de Meio Ambiente. Resolução n 303, de 20 de março de 2002. Brasília: DOU de 13/05/2002.

CONAMA - Conselho Nacional de Meio Ambiente. Resolução no 412, de 13 de maio de 2009. Brasília: DOU de 14/05/2009.

CONEMA - Conselho Estadual do Meio Ambiente. Dispõe sobre procedimentos para o Licenciamento Ambiental. Rio Grande do Norte, RN.

COPAM - Conselho de Proteção Ambiental. Decreto $n^{\circ}$ 21.120, de 20 de junho de 2000. Dispõe sobre a prevenção e controle da poluição ambiental. Paraíba, PB. Disponível em: < http://sudema.pb.gov.br/consultas/downloads/arquivoscopam/decreto_estadual_n-_21120.pdf > . Acesso em: 20 mar. 2017.

GIL, A. C. Métodos e técnicas de pesquisa social. 6. ed. São Paulo: Editora Atlas, 2008. 220 p.

IDEMA - Instituto de Desenvolvimento Sustentável e Meio Ambiente. Instituição: O Idema, 2012. Disponível em: < http://www.idema.rn.gov.br/Conteudo.asp?TRAN = I$\mathrm{TEM} \& \mathrm{TARG}=481 \& \mathrm{ACT}=\& \mathrm{PAGE}=0 \& \mathrm{PARM}=\& \mathrm{LBL}=$ Instituti $\% \mathrm{E} 7 \% \mathrm{E} 30>$. Acesso em: jan. 2015.

ISERNHAGEN, I. A fitossociologia florestal no Paraná e os programas de recuperação de áreas degradadas: uma avaliação. Dissertação (Mestrado em Botânica) - UFPR, 2001.

PINTO-COELHO, R. M. Fundamento de ecologia. Porto Alegre: Artmed, 2002.

RIO GRANDE DO NORTE. Lei 272, de 03 de março de 2004. Dispõe sobre a Política e o Sistema Estadual do Meio Ambiente, as infrações e sanções administrativas ambientais, as unidades estaduais de conservação da natureza, institui medidas compensatórias ambientais, e dá outras providências. Natal: DOE de 17/03/2004. 
RIO GRANDE DO NORTE. Lei complementar $\mathrm{n}^{\circ} 272$, de 03 de maio de 2004. Dispõe Sobre A Política e O Sistema Estadual do Meio Ambiente. Rio Grande do Norte, RN.

SANCHEZ, L. E. Avaliação de impacto ambiental: conceitos e métodos. São Paulo: Oficina de Textos, 2008.

SCHEIDT, F. S. da S.; SILVA, P. R. da; SILVA, S. M.; SILVA, C. P. da; HIROTA, E. H. Consideração de requisitos ambientais em empreendimentos habitacionais de interesse social: um estudo de caso. Ambiente Construído, Porto Alegre, v. 10, n. 1, p. 91106, jan./mar. 2010. Disponível em: < http://www.seer.ufrgs.br/ambienteconstruido/ article/viewFile/9426/7498 > . Acesso em: 20 mar. 2017.

SUDEMA - Superintendência de Administração do Meio Ambiente. Norma administrativa 108. Dispõe sobre a codificação de atividades poluidoras. Paraíba, PB.

Recebido em: 28/04/2017 Aceito em: 14/10/2017 